\title{
Risk factors for iron deficiency anaemia in preschool children in northern Ethiopia
}

\author{
AA Adish $^{1,2, *}$, SA Esrey ${ }^{1,3,4}$, TW Gyorkos ${ }^{4,5}$ and T Johns ${ }^{1}$ \\ 'School of Dietetics and Human Nutrition, Macdonald Campus of McGill University, 21, 111 Lakeshore Road, \\ St Anne-de-Bellevue, Quebec H9X 3V9, Canada: \\ 2Jimma Institute of Health Sciences, Ethiopia: \\ ${ }^{3}$ UNICEF, 3 UN Plaza, New York, NY 10017, USA: \\ ${ }^{4}$ Department of Epidemiology and Biostatistics, McGill University, Montreal, Quebec, Canada: \\ ${ }^{5}$ Division of Clinical Epidemiology, Montreal General Hospital, Montreal, Quebec, Canada
}

Submitted 10 May 1998: Accepted 30 July 1998

\begin{abstract}
Objective: To determine risk factors for anaemia in preschool children.

Design: A cross-sectional study.

Setting: Tigray province, northern Ethiopia.

Subjects: 2080 of 2373 children aged 6-60 months provided blood to assess anaemia.

Results: Anaemia was highly prevalent (42\%) and constituted an important nutritional problem in the region. In a sub-sample of 230 anaemic children, 56\% had a low red blood cell (RBC) count, and 43\% had a serum ferritin of less than $12 \mu \mathrm{g} \mathrm{l}^{-1}$ indicating that the anaemia was largely due to iron deficiency. Unlike other regions in developing countries, hookworm $(0.4 \%)$ and malaria $(0.0 \%)$ were rare and contributed little to the anaemia. Even though their diet lacked variety, the amount of iron consumed through cereal-based staple foods was adequate. However, the iron in these foods was not readily available and their diets were probably high in iron absorption inhibitors and low in enhancers. Dietary factors associated with anaemia included frequent consumption of inhibitors, such as fenugreek and coffee, and poor health in the child such as diarrhoea and stunting.

Conclusions: Underlying causes of anaemia were lack of safe water and inadequate human waste management, maternal illiteracy and mother being ill, and having no food reserves. The root cause of these factors was poverty. The optimal control strategy for iron deficiency anaemia should have a holistic approach which includes the alleviation of poverty, the empowerment of women and the provision of a safe environment.
\end{abstract}

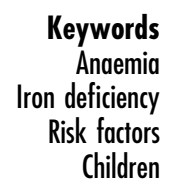

Iron deficiency anaemia is a common nutritional problem throughout the world and of enormous public health concern in developing countries. An estimated 36\% of the developing world's population suffer from anaemia. Preschool children in Africa have some of the highest rates of anaemia in the worldnearly $56 \%^{1}$. In Ethiopia, the magnitude and importance of iron deficiency anaemia as a public health problem is still disputed. Some studies reported iron deficiency anaemia rates of less than $18 \%{ }^{2,3}$ while others have reported rates of $25 \%$ and above ${ }^{4-6}$. Iron deficiency is a function of the imbalance of iron intake, iron absorption and iron loss ${ }^{7-9}$. In several developing countries the intake of iron from diet is more than adequate. For example, in parts of Ethiopia, the daily intake of iron is estimated to be between 180 and $500 \mathrm{mg} \mathrm{day}^{-1}$ which is 10-20 times the suggested daily requirement ${ }^{2,10}$. This presumed high intake is attributed to consumption of a staple cereal, teff or Eragrostis teff (90 $\mathrm{mg}$ of iron per $100 \mathrm{~g}$ of teff), and partly due to its contamination with iron-rich clay soil ${ }^{2}$. In spite of this high intake of iron, some studies have reported a high prevalence of anaemia, even in teff-consuming communities ${ }^{4,11}$. Therefore, the cause of iron deficiency in Ethiopia may not be the inadequate dietary intake of iron. Other factors, ultimately related to poverty and underdevelopment, might also play a role in iron deficiency anaemia ${ }^{12-14}$. In such communities with an already high intake of iron, the conventional supplementation of iron might not be effective or might even be harmful. Therefore, all important risk factors have to be identified and their role in causing anaemia evaluated. The objective of this study was to identify these risk factors and assess their role in anaemia. 


\section{Methods}

\section{Design}

A cross-sectional survey $(n=2373)$ was undertaken between September and December 1993 in Tigray province to determine household food security status of families with preschool children and identify risk factors for iron deficiency anaemia in children between the ages of 6 and 60 months. Haematocrit was used to assess anaemia, which was defined as a haematocrit of less than 34\%. (People of African origin have 2-3\% lower haematocrit than people of European origin and at an altitude of $2000 \mathrm{~m}$ above sea level there is a $0.5 \%$ increase due to long-term exposure to high altitude ${ }^{15}$.)

\section{Subjects and place of study}

This study included the city of Mekele in northern Ethiopia and the two surrounding semiurban communities (Quiha and Aynalem). In these communities a house-to-house census was conducted to identify households with children between 6 months and 5 years of age. After the census, only those children who were permanent residents of the study area (whose families had lived in the study area for at least 12 months prior to the study) were considered eligible to participate. In situations where families had two or more children in the target age group, the names of the children were written on a piece of paper and the one child whose name was picked randomly was selected for the study. Children who were severely febrile, in respiratory distress or who had a disability were excluded from the study for ethical reasons. Before the interview parental consent was obtained for each child.

\section{Sub-sample selection}

Invasive and/or expensive procedures, such as blood indices, serum ferritin and weighed food records, necessary to determine the type of anaemia, were performed in a sub-sample of 230 children selected at random, using a random number generator. The 230 children were selected from 877 children found to have a haematocrit less than $34 \%$ and aged between 24 and 60 months of age. Out of these 877 children, stool specimens were collected from 309 children who could produce stools at the time of the physical check-up and anthropometric measurement.

\section{Data collection}

The following information was obtained from 2373 mothers during a face-to-face interview and recorded onto a questionnaire: health and nutritional status of the child, such as age, gender, illness in the 2 weeks prior to the interview, presence and type of diarrhoea in the last 1 week (at least three loose stools in 1 day) and whether the child was being breastfed at the time of interview; maternal caring capacity, such as age of the mother, literacy (mother being able to read and write), religion, ethnicity, marital status and health status during the interview; environmental services, such as human excreta management (open field vs. latrine), source of drinking water (pipe water vs. water from unprotected spring, river or well), presence of soap in the house during the interview and number of rooms in the family dwelling; and food security variables, such as the family having food reserves, if the family received any food assistance in the 6 months prior to the interview and family's monthly income. Additional indirect information such as residence ownership and ownership of a radio were also used as a proxy measure of economic status. For all the children, food type and frequency of consumption in the 1 week prior to the interview were reported using a food frequency questionnaire ${ }^{16}$.

The questionnaire was developed in English, translated into the local language (Tigrigna), and pretested in non-study households in a similar community before application. Interviewers were periodically retrained on interviewing techniques and were supervised by trained field supervisors to maintain consistency in information gathering. Finally, mothers were given appointments to bring their children to the local clinic for a physical check-up by a medical practitioner.

Weight (Seca 770, Hamburg, Germany) and recumbent crown-heel length (Shorr Corp., Maryland, USA) were measured in duplicate using standardized protocols ${ }^{17}$. The child's age was obtained from the mother, recorded to the nearest month and crosschecked by a local events calendar ${ }^{16}$. Haematocrit was measured from the volume of erythrocytes as a percentage of the total sample volume after centrifugation of heparinized capillary blood from a finger prick ${ }^{17}$.

Three months after the interview, in-depth laboratory analyses were undertaken in the sub-sample of the 230 anaemic children. Since the food frequency questionnaire records only type of food with frequency of consumption, it was supplemented by the weighed food record (WFR) in the sub-sample of 230 children. The WFR was used to identify exact nutrient intakes of individual children ${ }^{15}$. Interviewers were assigned to follow each child for 24 hours and to record all food and beverages he/she consumed. Duplicate 24-hour measures were taken for each child ${ }^{15}$. The mean of the two measures was used to calculate the nutrient contents of the foods consumed using the table of food composition for use in Ethiopia ${ }^{18}$. Test weighing was performed for children being breastfed at the time of the interview. In the test weighing the net weight of the milk was determined by deducting the child's weight before breastfeeding from his weight after breastfeeding ${ }^{19}$. Then the net weight of milk consumed was converted into its appropriate nutrients using the table. 
For serum analysis, whenever possible, as much as $10 \mathrm{ml}$ of blood was collected from the antecubital vein using anticoagulated and trace mineral-free vacutainer tubes. The blood was then centrifuged and the serum separated and stored in a deep freezer $\left(-20^{\circ} \mathrm{C}\right)$. Finally, the serum was transported to Canada in liquid nitrogen. Duplicate samples of serum were analysed for serum ferritin using a radio immunoassay method (Fisher Scientific Ltd, Montreal, Canada) ${ }^{20}$ and the mean of the two measures was then reported. In cases where the amount of serum collected was found to be inadequate for all the tests, the following priority order was followed: serum ferritin $(n=230)$, blood indices $(n=$ $200)$ and blood morphology $(n=197)$.

From the venous blood collected, 197 specimens were available for blood indices and peripheral blood film. To determine blood indices such as mean corpuscular volume (MCV), haemoglobin, haematocrit and RBC count, a Coulter counter (CBC 5, Coulter Electronics of Canada) was used. Mean corpuscular haemoglobin $(\mathrm{MCH})$ and mean corpuscular haemoglobin concentration (MCHC) were calculated from the above indices. To determine blood morphology, blood films were prepared and stained with Wright's stain ${ }^{21}$. The same slides were used for the diagnosis of malaria (thick and thin smear) and a sickle cell blood picture. Stool specimens were examined by direct microscopic examination. A drop of saline was added to the stool before being analysed under the microscope.

All specimens, except serum, were analysed in a laboratory in Mekele on the same day. To avoid any possible transmission of hepatitis B or human immunodeficiency virus (HIV), all lancets and vacutainers used to draw blood were disposable. The laboratory technicians were given appropriate training on sterilization techniques. Duplicate specimens were averaged and duplicate readings of single specimens (e.g. stool) was done to minimize errors. The study was approved by the ethics review committees of the School of Dietetics and Human Nutrition at McGill University in Canada and the Jimma Institute of Health Sciences in Ethiopia.

\section{Data analysis}

All data were first recorded onto precoded questionnaires and laboratory forms and then entered into a computer using Epi Info ${ }^{22}$ and analysed using Stata ${ }^{23}$. All statistical analysis tests were two-tailed, and a type I error rate of $5 \%$ was used for $P$ values and confidence intervals.

Data were initially described and summarized using univariate statistics to document their distribution in the community. The variables were then assessed for their association with anaemia using the chi-square test. Continuous variables such as age and income were categorized into dichotomous variables: age $<24$ months and $\geqslant 24$ months; income below or above the poverty line (200 Birr or 32.2 US\$) (AB Kello, personal communication). Those variables with insufficient variance in the population $(<2 \%$ or $>98 \%)$ such as ethnicity, religion and car and motorbike ownership, were excluded from the analysis. Those variables found to have a significant crude association with anaemia $(P<0.05)$ were then entered into a multiple logistic regression analysis, to see if the crude association persisted after simultaneously adjusting for potential confounders. Even though it did not show a significant crude association, gender was included in the model because it was suspected to be a potential confounder a priori. To rule out misclassification of anaemia due to the cut-off used, a separate analysis was carried out by comparing children at both ends of the anaemia spectrum (i.e. children with a haematocrit $<30 \%$ vs. children with a haematocrit $>40 \%$ ).

\section{Results}

\section{Prevalence and type of anaemia}

Of the initial 2373 children studied, haematocrit results were available for 2080 (88\%) children. The mean haematocrit was $35.4 \pm 4.8 \%$, and $42 \%$ of children were anaemic. Of those 293 children for whom the haematocrit was not available, two-thirds did not give blood, while in the remaining one-third, the blood specimens were damaged either during transportation or during laboratory analysis. However, these children were not statistically different for any of the following characteristics - age, gender, the occurrence of illness in the 2 weeks prior to the interview, presence and type of diarrhoea, whether the child was breastfed, mother's literacy status, family's human waste management, source of drinking water, number of rooms in the family residence and family income-compared to children for whom a haematocrit level could be determined.

In the random sub-sample of 230 children with a haematocrit of less than $34 \%$, the mean serum ferritin level was $22.5 \mu \mathrm{gl}^{-1}$. Forty-three per cent of these

Table 1 Blood morphology in anaemic (haematocrit $<34 \%$ ) children aged $24-60$ months in Tigray, northern Ethiopia, December 1993

\begin{tabular}{lcr}
\hline Blood morphology & Frequency & Per cent \\
\hline Normocytic normochromic & 155 & 78.7 \\
Microcytic hypochromic & 34 & 17.2 \\
Macrocytic hyperchromic & 2 & 1.0 \\
Anisocytosis & 3 & 1.5 \\
Target cells & 3 & 1.5 \\
Total $^{*}$ & 197 & 100.0 \\
\hline
\end{tabular}

* Blood morphology was determined in 197 of the 230 children in the subsample. 
Table 2 Red blood cell indices and proportion of children who fall below the reference cut-off points in anaemic (haematocrit <34\%) children* aged 24-60 months in Tigray, northern Ethiopia, December 1993

\begin{tabular}{lccr}
\hline Indices & Mean \pm SD & Cut-off $\dagger$ & \% $<$ Cut-off \\
\hline Red blood cell count $\left(\mathrm{mm}^{3}\right)$ & $4.0 \times 10^{6} \pm 0.87 \times 10^{6}$ & $3.8 \times 10^{6}$ & 56.2 \\
Mean cell volume $(\mathrm{fl})$ & $73 \pm 6$ & 80 & 92.0 \\
Mean cell haemoglobin concentration $\left(\mathrm{g} \mathrm{dl}^{-1}\right)$ & $40 \pm 4.9$ & 32 & 4.1 \\
Mean cell haemoglobin $(\mathrm{pg})$ & $30.4 \pm 5.5$ & 27 & 29.5 \\
\hline
\end{tabular}

* Data were available from 200 of the 230 children.

† Normal cut-off values for each index were taken from Vaughan et al. ${ }^{24}$.

Table 3 Mean daily nutrient intakes (weighed food record) as compared to their recommended nutrient intakes (RNIs) in 230 anaemic (haematocrit $<34 \%$ ) children aged 24-60 months in Tigray, northern Ethiopia, December 1993

\begin{tabular}{lcccc}
\hline Nutrient & $\mathrm{RNI}^{*}$ & Mean & \% of RNI & $\%<\mathrm{RNI \dagger}$ \\
\hline Calories (kcal) & 1560 & $1218 \pm 460$ & 78 & 78 \\
Protein (g) & 26 & $44.6 \pm 40$ & 223 & 27 \\
Iron (mg) & $20 \ddagger$ & $110 \pm 120$ & 550 & 4 \\
Calcium (mg) & 600 & $293 \pm 168$ & 61 & 89 \\
Niacin (mg) & 9 & $8.7 \pm 6.7$ & 104 & 61 \\
Thiamin (mg) & 0.6 & $1.7 \pm 1.7$ & 283 & 99 \\
Riboflavin (mg) & 0.8 & $0.8 \pm 0.5$ & 102 & 60 \\
Vitamin A (RE) & 300 & 325 & 108 & 41 \\
Ascorbic acid (mg) & 20 & $63 \pm 73$ & 315 & \\
\hline
\end{tabular}

${ }^{*}$ Recommended nutrient intake from Health and Welfare Canada ${ }^{25}$.

† After corrections for difference in age were made.

$\ddagger$ RNI for children with cereal-based diet.

$\mathrm{RE}=$ retinol equivalents

children had serum levels of less than $12 \mu \mathrm{g} 1^{-1}$. Results on blood morphology were available from 197 children. Twenty per cent of the slides showed either a microcytic hypochromic, anisocytosis or target cell blood picture of iron deficiency anaemia while only two slides (1.0\%) indicated a macrocytic hyperchromic picture (Table 1). Most of the slides (78.7\%) were normocytic and normochromic. None of the slides were positive for malaria or sickle cell blood picture. The mean RBC count was $4.0 \times 10^{6} \mathrm{~mm}^{-3}$ and $56.2 \%$ of children had values below $3.8 \times 10^{6} \mathrm{~mm}^{-3}$ (Table 2). Almost all the children (92\%) had an MCV less than the normal cut-off point.

Only $4 \%$ of the study children had an iron intake of less than their daily recommended nutrient intake (RNI) (Table 3). Markedly lower intakes than the RNI

Table 4 Prevalence and type of intestinal parasites in anaemic (haematocrit $<34 \%$ ) children aged 6-60 months in Tigray, northern Ethiopia, December 1993

\begin{tabular}{lcr}
\hline Parasite & Frequency & Per cent \\
\hline Negative & 133 & 43.0 \\
Single parasite & 42 & 13.6 \\
$\quad$ Entamoeba histolytica & 38 & 12.3 \\
Hymenolepsis nana & 28 & 9.1 \\
Ascaris lumbricoides & 26 & 8.4 \\
Giardia lamblia & 1 & 0.4 \\
Schistosoma mansoni & 1 & 0.4 \\
Taenia spp. & 1 & 0.4 \\
Hookworm & 1 & 0.4 \\
Enterobius vermicularis & & \\
Two parasites & 10 & 3.4 \\
E. histolytica and H. nana & 8 & 2.6 \\
H. nana and A. lumbricoides & 3 & 1.0 \\
E. histolytica and G. lamblia & 2 & 0.7 \\
A. lumbricoides and T. trichiura & & \\
Three parasites & 6 & 2.0 \\
E. histolytica, H. nana and A. lumbricoides & 3 & 0.6 \\
E. histolytica, A. lumbricoides and Taenia spp. & 3 & 0.6 \\
H. nana, G. lamblia and Taenia spp. & 2 & 0.7 \\
A. lumbricoides, H. nana and E. vermicularis & 1 & 0.4 \\
E. histolytica, A. lumbricoides and S. mansoni & 309 & 100.0 \\
Total* & &
\end{tabular}

* Stool was obtained from 309 of the 877 anaemic children. 
Table 5 Univariate analysis of association of risk factors with anaemia in children aged 6-60 months in Tigray, northern Ethiopia, December 1993

\begin{tabular}{|c|c|c|c|}
\hline Risk factors & $\begin{array}{c}\% \text { anaemic } \\
(n=877)\end{array}$ & $\begin{array}{c}\% \text { non-anaemic } \\
\quad(n=1203)\end{array}$ & OR $(95 \% \mathrm{Cl})$ \\
\hline $\begin{array}{l}\text { Food intake variables } \\
\text { Child ate fenugreek in past } 7 \text { days } \\
\text { Child drank coffee in past } 7 \text { days } \\
\text { Child not breastfed } \\
\text { Child ate beef in past } 7 \text { days } \\
\text { Child ate injera in past } 7 \text { days } \\
\text { Child ate kale in past } 7 \text { days } \\
\text { Child ate orange in past } 7 \text { days }\end{array}$ & $\begin{array}{r}8.8 \\
9.4 \\
71.7 \\
4.9 \\
83.0 \\
4.6 \\
18.5\end{array}$ & $\begin{array}{r}6.4 \\
6.9 \\
64.9 \\
5.4 \\
84.6 \\
6.0 \\
20.5\end{array}$ & $\begin{array}{l}1.41(1.02-1.95) \\
1.39(1.01-1.91) \\
1.37(1.13-1.65) \\
0.91(0.60-1.37) \\
0.89(0.70-1.12) \\
0.75(0.51-1.11) \\
0.88(0.71-1.10)\end{array}$ \\
\hline $\begin{array}{l}\text { Disease-related variables } \\
\text { Child had diarrhoea in past } 7 \text { days } \\
\text { Child had fever in past } 7 \text { days } \\
\text { Child was stunted }<-2 \text { SD } \\
\text { Child had cough in past } 7 \text { days } \\
\text { Child was wasted }<-2 \text { SD } \\
\text { Child underweight }<-2 \text { SD }\end{array}$ & $\begin{array}{l}34.4 \\
50.9 \\
36.5 \\
42.5 \\
10.0 \\
37.9\end{array}$ & $\begin{array}{r}29.0 \\
46.2 \\
32.1 \\
43.0 \\
9.2 \\
33.8\end{array}$ & $\begin{array}{l}1.29(1.07-1.55) \\
1.20(1.01-1.43) \\
1.22(1.00-1.47)^{2} \\
0.99(0.82-1.17) \\
1.09(0.80-1.49)^{3} \\
1.20(0.99-1.45)^{4}\end{array}$ \\
\hline $\begin{array}{l}\text { Environmental and health service varia } \\
\text { Family used unsafe water } \\
\text { Family used open field waste disposal } \\
\text { Presence of soap in vicinity } \\
\text { Child born at home }\end{array}$ & $\begin{array}{l}14.6 \\
45.9 \\
61.0 \\
72.0\end{array}$ & $\begin{array}{l}21.1 \\
51.8 \\
63.6 \\
70.0\end{array}$ & $\begin{array}{l}1.56(1.24-1.96) \\
1.27(1.03-1.51)^{5} \\
0.89(0.75-1.07) \\
1.12(0.93-1.37)\end{array}$ \\
\hline $\begin{array}{l}\text { Maternal caring capacity variables } \\
\text { Mother illiterate } \\
\text { Mother ill in past } 7 \text { days } \\
\text { Mother }>40 \text { years } \\
\text { Mother pregnant during interview } \\
\text { Mother living with a partner } \\
\text { Mother did not attend health and } \\
\text { nutrition education }\end{array}$ & $\begin{array}{r}50.3 \\
28.6 \\
11.5 \\
9.7 \\
86.0 \\
69.6\end{array}$ & $\begin{array}{r}44.2 \\
23.9 \\
12.0 \\
8.7 \\
84.0 \\
68.9\end{array}$ & $\begin{array}{l}1.27(1.07-1.52) \\
1.27(1.04-1.55) \\
1.00(0.76-1.31) \\
1.12(0.83-1.51) \\
1.17(0.91-1.49) \\
1.03(0.85-1.24)\end{array}$ \\
\hline $\begin{array}{l}\text { Food security variables } \\
\text { Child } 24-60 \text { months } \\
\text { Family lived in one room } \\
\text { Family had no food reserves } \\
\text { Male child }\end{array}$ & $\begin{array}{l}74.5 \\
77.5 \\
30.7 \\
54.1\end{array}$ & $\begin{array}{l}65.8 \\
72.9 \\
26.7 \\
50.4\end{array}$ & $\begin{array}{l}1.52(1.25-1.83) \\
1.28(1.04-1.56) \\
1.21(1.00-1.48) \\
1.17(0.98-1.39)\end{array}$ \\
\hline $\begin{array}{l}\text { Poverty-related variables } \\
\text { Family lived below poverty line } \\
\text { Family did not own a radio } \\
\text { Family did not own their residence }\end{array}$ & $\begin{array}{l}83.5 \\
70.9 \\
45.6\end{array}$ & $\begin{array}{l}79.9 \\
64.0 \\
45.6\end{array}$ & $\begin{array}{l}1.33(1.05-1.68)^{6} \\
1.32(1.09-1.58) \\
1.00(0.84-1.19)\end{array}$ \\
\hline
\end{tabular}

were observed for niacin (61\%), riboflavin (59\%) and ascorbic acid (41\%). The majority of the children (78\%) had caloric intakes less than their recommended daily requirements and about a quarter of the children had less than the recommended daily protein requirement.

Among the 309 children for whom a stool test for parasites was performed, more than half of the children were found to have at least one intestinal parasite (Table 4). The most common single and mixed parasites observed were Hymenolepsis nana (21.6\%), Entamoeba histolytica (21.0\%), Ascaris lumbricoides (16.1\%) and Giardia lamblia (10.0\%). Hookworm infection (0.4\%) and infections of Schistosoma mansoni $(0.8 \%)$, Trichuris trichiura (0.7\%) and Schistosoma haematobium $(0.0 \%)$, which are often associated with anaemia, were rarely detected.

\section{Univariate analysis of associations of risk factors with anaemia}

For analysis, similar variables were re-grouped under key risk categories: food intake, disease-related variables, variables related to health and environmental services, maternal caring capacity variables, food security variables and poverty-related variables (Table 5). Variables which do not belong to any of these groups, such as age and gender, were included under the food security variables category for convenience of analysis.

\section{Food intake variables}

Injera, a local bread made of teff, was consumed by $83 \%$ of all children at least once a week. Meat and vegetables were consumed infrequently by only $5 \%$ of the children. Children who were reported to have 
Table 6 Crude and adjusted associations of selected risk factors with anaemia at different cut-off points in children aged 6-60 months in Tigray, northern Ethiopia

\begin{tabular}{|c|c|c|c|c|}
\hline \multirow[b]{2}{*}{$\begin{array}{l}\text { Risk factor } \\
\text { (reference category) }\end{array}$} & \multicolumn{2}{|c|}{$\begin{array}{l}\text { Haematocrit } \geqslant 34 \% \\
\text { vs. } \\
\text { haematocrit }<34 \%\end{array}$} & \multicolumn{2}{|c|}{$\begin{array}{c}\text { Haematocrit }<30(n=370) \\
\text { vs. } \\
\text { haematocrit }>40 \%(n=296)\end{array}$} \\
\hline & $\begin{array}{c}\text { Crude } \\
\text { OR }(95 \% \mathrm{Cl})\end{array}$ & $\begin{array}{c}\text { Adjusted } \\
\text { OR }(95 \% \mathrm{Cl})^{*}\end{array}$ & $\begin{array}{c}\text { Crude } \\
\text { OR }(95 \% \mathrm{Cl})\end{array}$ & $\begin{array}{c}\text { Adjusted } \\
\text { OR }(95 \% \mathrm{Cl}) \dagger\end{array}$ \\
\hline \multicolumn{5}{|l|}{ Food intake variables } \\
\hline $\begin{array}{l}\text { Child consumed fenugreek in past } 7 \text { days } \\
\text { (did not consume) }\end{array}$ & $1.41(1.02-1.95)$ & $1.28(0.89-1.85)$ & $2.65(1.50-4.68)$ & $1.98(1.04-3.74)$ \\
\hline $\begin{array}{l}\text { Child drank coffee in past } 7 \text { days } \\
\text { (did not drink) }\end{array}$ & $1.39(1.01-1.91)$ & $1.24(0.87-1.79)$ & $1.43(0.84-2.46)$ & $1.49(0.78-2.81)$ \\
\hline $\begin{array}{l}\text { Child not breastfed } \\
\text { (breastfed) }\end{array}$ & $1.37(1.13-1.65)$ & $1.20(0.90-1.58)$ & $1.86(1.32-2.61)$ & $1.51(0.89-2.55)$ \\
\hline \multicolumn{5}{|l|}{ Disease-related variables } \\
\hline $\begin{array}{l}\text { Child had diarrhoea in past } 7 \text { days } \\
\text { (no diarrhoea) }\end{array}$ & $1.29(1.07-1.55)$ & $1.13(0.90-1.41)$ & $1.33(0.96-1.85)$ & $1.22(0.80-1.86)$ \\
\hline $\begin{array}{l}\text { Child stunted }<-2 \text { SD } \\
\quad(\text { not stunted } \geqslant-2 S D)\end{array}$ & $1.22(1.00-1.47)$ & $1.10(0.89-1.37)$ & $1.65(1.18-2.28)$ & $1.42(0.96-2.09)$ \\
\hline $\begin{array}{l}\text { Child had fever in past } 7 \text { days } \\
\text { (did not have fever) }\end{array}$ & $1.02(1.01-1.43)$ & $1.14(0.92-1.41)$ & $1.28(0.95-1.74)$ & $1.16(0.77-1.75)$ \\
\hline \multicolumn{5}{|l|}{ Environment and health service variables } \\
\hline $\begin{array}{l}\text { Family used unsafe water } \\
\text { (safe water supply) }\end{array}$ & $1.56(1.24-1.96)$ & $1.36(1.04-1.80)$ & $2.24(1.49-3.36)$ & $1.81(1.09-3.00)$ \\
\hline $\begin{array}{l}\text { Open field waste disposal } \\
\text { (pit latrine) }\end{array}$ & $1.27(1.03-1.51)$ & $1.21(0.98-1.51)$ & $1.27(0.94-1.73)$ & $1.21(0.83-1.81)$ \\
\hline \multicolumn{5}{|l|}{ Maternal caring capacity variables } \\
\hline $\begin{array}{l}\text { Mother illiterate } \\
\text { (literate) }\end{array}$ & $1.27(1.07-1.52)$ & $1.21(0.98-1.50)$ & $1.51(1.11-2.05)$ & $1.43(0.96-2.11)$ \\
\hline $\begin{array}{l}\text { Mother ill in past } 7 \text { days } \\
\text { (mother was not ill) }\end{array}$ & $1.27(1.04-1.55)$ & $1.25(1.00-1.56)$ & $1.00(0.71-1.42)$ & $1.15(0.76-1.74)$ \\
\hline \multicolumn{5}{|l|}{ Food security variables } \\
\hline $\begin{array}{l}\text { Child } 24-60 \text { months old } \\
\quad(<24 \text { months of age })\end{array}$ & $1.52(1.25-1.83)$ & $1.71(1.26-2.32)$ & $2.07(1.47-2.92)$ & $2.49(1.41-4.39)$ \\
\hline $\begin{array}{l}\text { Male child } \\
\text { (female) }\end{array}$ & $1.17(0.98-1.39)$ & $1.18(0.96-1.44)$ & $1.29(0.95-1.75)$ & $1.39(0.96-2.02)$ \\
\hline $\begin{array}{l}\text { Family lived in one room } \\
\text { (more than one) }\end{array}$ & $1.28(1.04-1.56)$ & $1.22(0.95-1.57)$ & $1.01(0.72-1.44)$ & $1.07(0.68-1.70)$ \\
\hline $\begin{array}{l}\text { Family did not have food reserves } \\
\text { (had food reserves) }\end{array}$ & $1.21(1.00-1.48)$ & $1.31(1.04-1.64)$ & $1.68(1.21-2.33)$ & $1.74(1.15-2.64)$ \\
\hline \multicolumn{5}{|l|}{ Poverty-related variables } \\
\hline $\begin{array}{l}\text { Family lived below poverty line } \\
\text { (lived above poverty line) }\end{array}$ & $1.33(1.05-1.68)$ & $1.49(1.13-1.95)$ & $1.55(1.03-2.35)$ & $1.71(1.04-2.81)$ \\
\hline $\begin{array}{l}\text { Family did not own a radio } \\
\text { (owned a radio) }\end{array}$ & $1.32(1.09-1.58)$ & $1.16(0.92-1.47)$ & $1.50(1.61-2.08)$ & $1.19(0.77-1.85)$ \\
\hline
\end{tabular}

The multivariate analysis included children for whom information on all variables included in the logistic regression model were complete: $n=1691^{*}$ and $566+$.

consumed iron absorption inhibitors, such as fenugreek and coffee, were 1.4 times more at risk of anaemia than children who did not consume these beverages. Non-breastfed children were also at increased risk of anaemia compared to children who were breastfed. Injera and kale, foods high in iron, did not show a significant protective effect against anaemia. Oranges (high in ascorbic acid) also did not show a significant protective effect.

\section{Disease-related variables}

According to the mothers' perception of the health status of their children, $27 \%$ indicated that they considered their children had poor health while the rest were considered to have average or good health. Nearly half of the children had fever in the week prior to the interview and between one-third to one-half of the children had diarrhoea or cough. According to their mothers, $68 \%$ of children had good or average growth and this corresponded well with the percentage of stunted and underweight children in the study. Three of these variables were significantly associated with anaemia. Children with diarrhoea or fever and stunted children were at significantly greater risk for anaemia than their referent counterparts.

\section{Environmental and health service variables}

Half (48\%) of the families used open fields for human waste management. When the availability of clean water was assessed, $82 \%$ of households were getting piped water. However, the majority of these households bought water from public water stands. A 
majority of mothers (75\%) visited health institutions and $70 \%$ had attended health and nutrition sessions in the 2 weeks prior to the interview.

Children had increased risk of anaemia $(\mathrm{OR}=1.56)$ if their families used unsafe water sources for drinking or reported inadequate waste management $(\mathrm{OR}=1.27)$. The presence of soap in the vicinity at the time of the interview was not indicative of anaemia. Children born at home did not have any increased risk of anaemia compared with children born in health institutions, nor was attendance at health and nutrition sessions associated with increased risk.

\section{Maternal caring capacity variables}

The mean age of mothers in the study was $29 \pm 7.6$ years. Thirty-eight per cent of mothers were 25 years old or younger and only $8 \%$ were 45 years or older. Most mothers were living with their partners (85\%) while the remaining $15 \%$ were either divorced, separated or widowed. The maternal literacy rate was $48 \%$.

Several maternal caring capacity factors were associated with increased risk of anaemia. Children of illiterate mothers and children whose mothers were sick during the interview had 1.27 times higher risks, compared to their referent counterparts. Neither maternal age nor being pregnant at the time of interview was significantly associated with anaemia in the child.

\section{Food security variables}

The study children had a mean age of 29 months, and boys $(51.7 \%)$ and girls (48.3\%) were equally represented. Most children lived in crowded and substandard houses. Even though half the families owned the house they lived in, the majority (75\%) were living in a single room. Almost $26 \%$ of families had no separate kitchen, hence the preparation and cooking of food took place in the same room as other family activities.

Children of families who lived in one room were 1.28 times more at risk of anaemia than children of families with more rooms, and children older than 24 months of age were more likely ( 1.5 times) to be anaemic than their referent counterparts. Children of families with no food reserves were 1.21 times more at risk for anaemia than children of families with food reserves. Gender differences did not show any association with anaemia.

\section{Poverty-related variables}

The majority of the study families were classified as living below the poverty line with $81 \%$ having a reported monthly income of less than 200 Birr. Less than half of the study families had access to a radio. Income below the poverty line was a predictor of anaemia $(O R=1.33)$. Proxy measures for wealth, such as ownership of a radio, also showed strong protective effects. Ownership of the family residence had no association with anaemia in the child.

\section{Multivariate analysis of selected risk factors}

The multivariate analysis included only the 1691 children for whom complete information on all variables included in the model was available (Table 6). When variables that showed a significant crude association with anaemia were included in a multiple logistic regression analysis, the association of the following variables with anaemia persisted after simultaneously controlling for the other variables: older children $(\mathrm{OR}=1.71)$, unsafe drinking water $(\mathrm{OR}=1.36)$, family not having food reserves $(\mathrm{OR}=1.31)$, mother being ill $(\mathrm{OR}=1.25)$ and income below the poverty line $(\mathrm{OR}=1.49)$.

The cut-off of anaemia at a haematocrit of less than $34 \%$ may result in misclassification bias. To rule out potential misclassification, a subsequent multivariate analysis was undertaken comparing children at the extremes (haematocrit $<30 \%$ and haematocrit $>40 \%$ ) (Table 6). The odds ratios and confidence intervals for nearly all the variables in the model were strengthened: for children more than 24 months of age $(\mathrm{OR}=2.49)$, for children of families with unsafe drinking water $(\mathrm{OR}=1.81)$, for children of families that did not have food reserves $(\mathrm{OR}=1.74)$, and for children of families living below the poverty line $(\mathrm{OR}=1.71)$. In addition, children who consumed fenugreek were also at increased risk $(\mathrm{OR}=1.98)$. Stunting $(\mathrm{OR}=1.42)$, inadequate waste management $(\mathrm{OR}=1.21)$, illiterate mother $(\mathrm{OR}=1.43)$ and being male $(\mathrm{OR}=1.39)$ showed trends of increased risk.

\section{Discussion}

Nearly half the study children, residing in urban and semiurban communities, had anaemia, largely due to iron deficiency. Investigators in other parts of the country have also reported similar results ${ }^{4-6}$. The commonest abnormal blood morphology observed was microcytic hypochromic, a blood picture common in iron deficiency anaemia. Only 1.0\% of blood slides showed a macrocytic hyperchromic picture of megaloblastic anaemia common in vitamin $\mathrm{B}_{12}$ and/or folic acid deficiencies. The normal blood morphology observed in most anaemic children is due to the fact that these parameters change in the advanced stages of iron deficiency anaemia, and are characteristic of severe cases of iron deficiency anaemia ${ }^{26}$. Furthermore, the low mean serum ferritin level $\left(22 \mu \mathrm{gl}^{-1}\right)$, the high proportion of children with serum ferritin levels of less than $12 \mu \mathrm{gl}^{-1}(43.2 \%)^{15}$ and the high rates of low MCV and $\mathrm{MCH}$ in the study children confirm that the anaemia was due to iron deficiency. Low MCV is a relatively specific index for iron deficiency. MCV and 
$\mathrm{MCH}$ are always high and MCHC may be high or normal in macrocytic hyperchromic anaemia of vitamin $\mathrm{B}$ and folate deficiency ${ }^{15}$. An iron supplementation trial in a sub-sample of the anaemic children showed an increase in both haemoglobin and haematocrit ${ }^{27}$, which is diagnostic of iron deficiency.

In general, prevalence of iron deficiency is higher in infants up to 2 years of age compared to older preschool children. Iron in breast milk is highly available, and in this sample children breastfed well into the second year of life. Therefore, breastfeeding may have provided protection during the first years of life.

Haematocrit is an easy and rapid test, but is subject to limitations as a screening tool. It is less sensitive compared to haemoglobin or cyanmethaemoglobin methods ${ }^{16}$. One limitation is that during iron deficiency the haematocrit falls only after haemoglobin formation is impaired. Thus, use of only haemocrit may underestimate the true prevalence of anaemia in children with marginally low haemoglobin values ${ }^{16}$.

Malaria, which is one of the commonest causes of anaemia in other parts of the country ${ }^{11}$, was absent in the study communities. Low rates of parasites such as hookworm, schistosomes and whipworm probably reflect the nature of the soil and dry climate of the study area ${ }^{28}$. The commonest parasites in the study area were E. histolytica and $H$. nana. While causing mucoid or bloody diarrhoea, it would be difficult to attribute the occurrence of anaemia in the study area to these parasites. Although direct microscopy of unconcentrated stool is less precise than the other microscopic techniques in diagnosing intestinal parasites, it is widely recognized as a suitable method to estimate overall levels of community infection.

It is believed that inadequate intake of iron is one of the most important factors in iron deficiency anaemia, but iron intake was the least important risk factor. Thus, the conventional approach of controlling iron deficiency by iron supplementation alone may have little value. Children obtain their iron from plant (nonhaem) sources, mainly teff, which is very rich in iron and was consumed by almost all children at least once a week. However, meat and other foods rich in ascorbic acid, which improve the absorption of non-haem iron, were rarely consumed ${ }^{29}$. Roodenburg is of the opinion that pregnant women could meet their iron requirement merely by increasing iron absorption efficiency ${ }^{30}$. A study by Sharma and Mathur showed that $500 \mathrm{mg}$ of ascorbic acid twice a day significantly improved the haemoglobin, serum iron, serum ferritin and transferrin saturation levels of 28 strict vegetarians ${ }^{31}$. Similar results in Chinese children with mild anaemia were reported by $\mathrm{MaO}^{32}$.

It is also known that diets in developing countries, including the study area, lack variety and contain substances that inhibit the absorption of iron, such as tannins, phenols and fibre ${ }^{33}$. Fenugreek, which is rich in mucilaginous fibre ${ }^{34}$, and coffee and tea, known to inhibit iron absorption ${ }^{35}$, were also consumed by some children. Therefore, in this study the immediate cause of iron deficiency anaemia may be due not so much to inadequate intake as to the low efficiency of iron absorption. In the study community, immediate control strategies should include improving food processing and better timing of the intake of beverages. Investigators have reported that fermenting cereals and legumes and taking coffee or tea at least 3 hours after meals will reduce their inhibitory effect ${ }^{17}$. This was a cross-sectional study and it was conducted after the harvest season and may, therefore, reflect a best case scenario. Dietary information at other times of the year was not available, but efforts should be made to increase the consumption of foods that enhance the absorption of iron throughout the year.

No single risk factor was identified as a predominant predictor of iron deficiency anaemia. Odds ratios of 2.0 or less suggest the multifactorial nature of iron deficiency anaemia. The major risk factors identified were related to inadequate environmental conditions, constrained maternal caring capacity, food insecurity and poverty. Disease-related variables, such as diarrhoea and fever, were moderately associated with anaemia. Sick children are known to have poor appetite and hence a low dietary intake ${ }^{36}$. Low dietary intake in turn leads to low iron intake. Common infections are also known to impair haematopoiesis and consequently cause anaemia. Therefore, ill and/or malnourished children often have associated micronutrient deficiencies ${ }^{37}$. Children in this study had high levels of macronutrient deficiencies as reflected by their low caloric intake and high rate of stunting and wasting. The fact that most micronutrient deficiencies occur along with macronutrient deficiencies has also been reported by researchers in other parts of the world ${ }^{38}$.

The health benefits of clean water and adequate sanitation extend beyond those resulting from reduction of pathogens alone ${ }^{39}$. Access to clean water will benefit a woman's limited time, energy and income. If the time and energy saved is used by the mother to care for herself and her child, it will have a direct impact on the health and nutritional status of her children ${ }^{39}$. Although the majority of households were getting clean water for drinking, almost half of the households disposed of their waste in the open field, which is used as a playground by the children. Children in this study lived in crowded and substandard houses. Most households had mud floors and only one in four families had a separate kitchen facility. This poor personal and environmental sanitation was strongly associated with anaemia.

Women need to protect their own health and nutritional status to be able to fulfil their role as 
care-givers. Their level of education, knowledge of nutrition and employment status will determine in part whether they will have the understanding and the time to care for their children. Because children of illiterate mothers had a higher risk of anaemia, education may enhance a mother's ability to protect her child from contaminated environments and her ability to provide an appropriate diet.

Most families depended on relief assistance for most of the year. Having food reserves and more than one room in the family residence had strong negative associations with anaemia. Poverty constrains a family's ability to gain access to and control human, economic and organizational resources ${ }^{5}$. Access to and control of these resources would allow people to gain greater access to food, maternal and child care, and health and environmental services. The study community has been plagued by instability, drought and civil war, and the people have been deprived of human, organizational and economic resources. Iron deficiency is undoubtedly more common among groups of low socioeconomic status ${ }^{40}$.

Iron intake was more than adequate, but availability of iron was low. Supplementation to merely increase intake of iron may not be a long-term solution. Iron deficiency anaemia was multifactorial and the solution to address the problem must, therefore, be multidisciplinary. A sound iron deficiency control programme should place more emphasis on improving the efficiency of iron absorption and tackling the underlying causes of iron deficiency anaemia. The control programme should not neglect the importance of alleviating general poverty, empowering and educating women, improving personal and environmental hygiene, reducing disease burden and controlling macronutrient deficiencies.

\section{Acknowledgements}

The Relief Society of Tigray, REST, provided office space and facilitated community and government support for the project. We thank the staff of the Mekele Hospital, Mekele Health Center and Ethiopian Nutrition Institute for their material and technical support. Theresa Gyorkos received career award support from the National Health Research and Development Programme of Health Canada and from the Fonds de la Recherche en Santé du Québec. This research was funded by IDRC, the Steelworkers Humanity Fund of Canada and the Thrasher Research Fund.

\section{References}

1 United Nations, ACC/SCN. Controlling Iron Deficiency. Nutrition Policy Discussion, Paper No. 9. New York: United Nations, 1991.
2 Hofvander Y. Hematological investigations in Ethiopia with special reference to a high iron intake. Acta Med. Scand. 1968; 494: 11-74.

3 Gebre-medhin M, Kilander A, Bahlquist B, Wuhib E. Rarity of anaemia of pregnancy in Ethiopia. Scand. J. Haematol. 1976; 16: 168-75.

4 Zein ZA, Assefa M. The prevalence of anemia among populations living at different altitudes in north-western Ethiopia. Ethiop. Med.J. 1987; 25: 105-11.

5 Esrey SA, Adish AA, Barr G, Asefa T. Characteristics and Determinants of Nutritional Status in Tigray. IDRC report. Ottawa: IDRC, 1995.

6 Gebreselassie HM. Iron supplementation and malaria infection: results from a randomized controlled field trial. PhD thesis, McGill University, Montreal, Canada, 1997.

7 Baker SJ, DeMaeyer EM. Nutritional anemia: its understanding and control with special reference to the work of the World Health Organization. Am. J. Clin. Nutr. 1979; 32: 368-417.

8 Food and Agriculture Organization (FAO). Requirements of Vitamin A, Iron, Folate and Vitamin $B_{12}$. Report of a Joint FAO/WHO expert consultation. Rome: FAO/WHO, 1988.

9 Cook JD, Skikne BS, Baynes RD. Iron Deficiency: The Global Perspective. Progress in Iron Research. New York: Plenum Press, 1994: 219-28.

10 Interdepartmental Committee on Nutrition for National Defense. Ethiopia - Nutrition Survey. Washington DC: US Government Printing Office, 1959.

11 Ministry of Health of Ethiopia, MOH/WHO. Primary Health Care Review Ethiopia. Addis Abeba: Ministry of Health, 1987.

12 Foy H, Kondi A. Hookworm in the etiology of tropical iron deficiency anemia. Trans. R. Soc. Trop. Med. Hyg. 1960; 54: 419-33.

13 World Health Organization. Iron Deficiency Anemia. Technical Report Series no. 182. Geneva: WHO, 1959.

14 Layrisse M, Roche M. The relationship between anemia and hookworm infection. Am. J. Hyg. 1964; 79: 279-87.

15 World Health Organization. Report of the WHO/UNICEF/UNU Consultation on Indicators and Strategies for Iron Deficiency and Anemia Programmes. Geneva:WHO, 1994.

16 Gibson RS. Principles of Nutritional Assessment. New York: Oxford University Press, 1990.

17 United Nations. How to Weigh and Measure Children: Preliminary Version. New York: United Nations, 1986.

18 Agren G, Gibson R. Food Composition for Use in Ethiopia I. Addis Abeba: Ethiopian Nutrition Institute, 1964-1975.

19 World Health Organization. The Quantity and Quality of Breast Milk. Geneva: WHO, 1985.

20 International Nutritional Anemia Consultative Group (INACG). Measurement of Iron Status. Washington DC: The International Nutritional Anemia Consultative Group, 1985.

21 Powers LW. Diagnostic Hematology: Clinical and Technical Principles. St Louis: Mosby, 1989.

22 Center for Disease Control (CDC). Epi Info version 5. Atlanta: CDC, 1994.

23 Stata Corporation. Stata version 3.1. Texas: Stata Corporation, 1991

24 Vaughan VC, McKay RJ, Behrman RE, Nelson WE. Nelson Textbook of Pediatrics. Philadelphia: WB Saunders Company, 1979: 1375-8.

25 Health and Welfare Canada (HWC). Nutrition Recommendations: The Report of the Scientific Review Committee. Ottawa: HWC, 1990.

26 Braunwald E, Isselbacher KJ, Petersdorf RG, Wilson JD, Martin JB, Bauci AS. Harrison's Principles of Internal Medicine. New York: McGraw-Hill Company, 1987: 1489-98.

27 Adish AA, Esrey SA, Gyorkos TW, Jean-Baptiste J, Rojhani A. Effect of consumption of food cooked in iron pots on iron 
status and growth of young chirldren: randomised trial. Lancet 1999; 353: 712-16.

28 Stephenson L. Impact of Helminth Infection on Human Nutrition. London: Taylor \& Francis, 1987.

29 Mahiou C, Frappaz D, Freycon MT, Freycon F. Iron deficiency in infants and children (in French). Pediatrics 1992; 47: 551-5.

30 Roodenburg AJ. Iron supplementation during pregnancy. Eur. J. Obstet. Gynecol. Reprod. Biol. 1995; 61: 65-71.

31 Sharma DC, Mathur R. Correction of anemia and iron deficiency in vegetarians by administration of ascorbic acid. Ind. J. Physiol. Pharmacol. 1995; 39: 403-6.

32 Mao X, Yao G. Effect of vitamin C supplementations on iron deficiency anemia in Chinese children. Biomed. Environ. Sci. 1992; 5: 125-9.

33 Haghshenass M, Mahloudij M, Reinhold JG, Mohammadi N. Iron-deficiency in an Iranian population associated with high intakes of iron. Am. J. Clin. Nutr. 1972; 25: 1143-6.

34 Newall CA, Anderson LA, Phillipson JD. Fenugreek: Herbal Medicines, A Guide for Health Care Professionals. London: Pharmaceutical Press 1996, 117-18.

35 Hamdaoui M, Hedhili A, Doghri T, Tritar B. Effect of tea on iron absorption from the typical Tunisian meal 'couscous' fed to healthy rats. Ann. Nutr. Metabol. 1994; 38: $226-31$.

36 Lawless JW, Latham M, Stephenson LS, Kinoti SN, Perlet AM Iron supplementation improves appetite and growth in anemic Kenyan primary school children. J. Nutr. 1994; 124: $645-54$.

37 Committee on Nutrition. Relationship between iron status and incidence of infection in infancy. Pediatrics 1978; 62 246-50.

38 Pollitt E. Functional significance of the covariance between protein energy malnutrition and iron deficiency anemia. $J$. Nutr. 1995; 125: S2272-77.

39 Burger SE, Esrey SA. Water and sanitation: health and nutrition benefits to children. In: Pinstrup-Anderson $\mathrm{P}$, Pelletier D, Alderman H, eds, Child Growth and Nutrition in Developing Countries: Priorities for Action. Ithaca: Cornell University Press, 1995: 153-75.

40 Ahmed F, Mohiduzzam M, Barua S, et al. Effect of family size and income on the biochemical indices of urban school children of Bangladesh. Eur. J. Clin. Nutr. 1992; 46 $465-73$. 